\title{
Linking Engineering Service Courses with Engineering Design
}

\author{
P. David Fisher, James S. Fairweather, Diane T. Rover, Lisa A. Haston \\ Michigan State University
}

\begin{abstract}
This paper focuses on the important role engineering service courses could play in a student's major engineering design experience. It explores opportunities for students to apply knowledge acquired and skills learned in these courses to their multidisciplinary, engineering design experiences. But transforming these courses and linking them more formally to engineering design may require that engineering faculty and administrators rethink some of the traditional ways in which engineering service courses and engineering design courses function. Institutional impediments, which prevent or discourage students from different engineering — as well as nonengineering - disciplines from coming together to gain formal multidisciplinary teaming experiences, need to be identified and eliminated. Reforming engineering service courses appears to represent one important component in dealing effectively with these challenges.
\end{abstract}

I. Introduction: Traditional View of Engineering Service Courses

\section{Accreditation Requirements}

An engineering service course may be defined as a required or elective course taken by engineering students outside their principal field of study-e.g., an environmental engineering or computer engineering course taken by students majoring in mechanical engineering. While preparing for an EC2000 accreditation site visit to Michigan State University (MSU), several members of the College of Engineering faculty came to recognize that engineering service courses were often overlooked — or even discounted—in terms of their potential educational value $^{1,2}$. This conclusion became very evident when the faculty began the process of documenting how educational program objectives were actually being achieved within specific undergraduate engineering programs. By and large, MSU's engineering faculty viewed engineering service courses primarily as a longstanding engineering curricular mandate from ABET. This Engineering Topics curricular-content requirement is concisely stated as follows in a recent addition of ABET's Criteria for Accrediting Programs in Engineering in the United States ${ }^{3}$ :

"In order to promote breadth, the curriculum must include at least one engineering course outside the major disciplinary area."

Several faculty members began to look beyond this cryptic requirement to add breadth to engineering programs and asked the following important question:

"How might engineering services courses at be transformed so that they have an important impact on the program outcomes mandated in EC2000's Criterion $3^{4}$ ?" 
While several engineering service courses were considered simultaneously ${ }^{1,5}$, the discussion in this paper focuses on only one of these courses, ECE 345-Introduction to Electronic

Instrumentation Systems ${ }^{6}$. This course is offered by the Department of Electrical and Computer Engineering (ECE) and is required by students in four engineering majors. Five other programs designate it as an elective course. Electrical engineering and computer engineering majors are not allowed to receive credit for taking this course since they are required to take a more in depth sequence of courses. Students are introduced to electrical and electronic components, circuits and instruments. The circuit laws are applied to dc, ac, and transient circuit applications. Students are also introduced to digital logic fundamentals and gain experience in designing, building and testing simple logic circuits. A three-hour/week laboratory provides active learning experiences for the students.

\section{Results of Benchmarking}

We conducted a web-based search of other similar courses at other institutions to see what engineering service courses were required and how these courses were linked to major engineering design experiences. We selected the institutions and academic programs to benchmark by drawing upon the U.S. News \& World Report web site to identify the "best" engineering programs at institutions whose highest degree is a Ph.D. (Category I) and at institutions whose highest degree is a bachelor's or master's (Category II) ${ }^{7}$. This benchmarking process led us to the following general observations:

- Category I institutions tend to offer less required engineering service courses per academic program than Category II institutions. This in turn tends to have Category I academic programs focus more on depth topics within the specific engineering discipline while Category II academic programs tend to exhibit greater breadth across engineering topics.

- Some institutions offer a separate service course in electrical-engineering topics for nonmajors-which is the case at MSU-while others do not. Once again, there were noticeable differences between Category I and Category II institutions, with the latter tending to have more introductory engineering courses within the different majors. These courses are generally taken as require courses by majors and non-majors alike. For example, EE and nonEE majors would take an introductory course in electrical engineering.

- While some are sequences of two-semester courses, most are just one semester in length. With the former case, majors and non-majors alike generally tend to take the sequence of courses. Specific offerings for non-majors tend to be single courses only within a particular engineering major.

- Some require a laboratory as an integral part of the course - as is the case at MSU. Some, however, have a lecture with no laboratory experience. And, in some cases, there are lecture courses with separate laboratory courses as an option. Category I institutions tend to offer less required laboratory experiences within engineering service courses than Category II institutions.

This benchmarking exercise demonstrated that a wide variation exists among the various institutions with respect to how they require engineering services courses and, concomitantly, how material learned in one course is applied in follow-on engineering courses across the major. 
Category I institutions tended to focus on the engineering discipline, thereby limiting student opportunities for multi-disciplinary major engineering design experiences. On the other hand, Category II institutions appear to offer significant insight into how this goal can be achieved.

\section{Reform Opportunities}

\section{Engineering Design Experiences at MSU}

In the context of ABET's major engineering design requirement and EC2000 preparation, a new course model was developed for the capstone course in computer engineering, ECE 482Capstone: Computer System Design ${ }^{9}$. The learning objectives for the course state that students will learn about embedded systems, i.e., electrical systems that contain embedded computers to control processes. At the completion of the course, each student should have actively participated as a member of an engineering design team and made significant contributions to achieving the team's mission. Each design project involves the collaborative development and evaluation of a product that contains an embedded computer. Our experiences with this course have included three forms of multidisciplinary engineering design: cross-functional teaming, multidisciplinary projects, and multidisciplinary teaming. Cross-functional teaming (CFT) is a team-based course learning model that is the foundation for the course and a potential cornerstone for reform ${ }^{10}$.

In ECE 482, teaming is essential to accomplish the course learning objectives and complete a project. Design-team formation is a structured process that takes into account students' background and interests so as to create teams with the requisite diversity of expertise and perspective. Diversity of expertise is also developed just in time during the course through the use of CFT. Cross-functional teaming partitions students into two sets of interdependent teams, "design teams" and "skill teams". Design teams are formed for the entire semester. Each of these

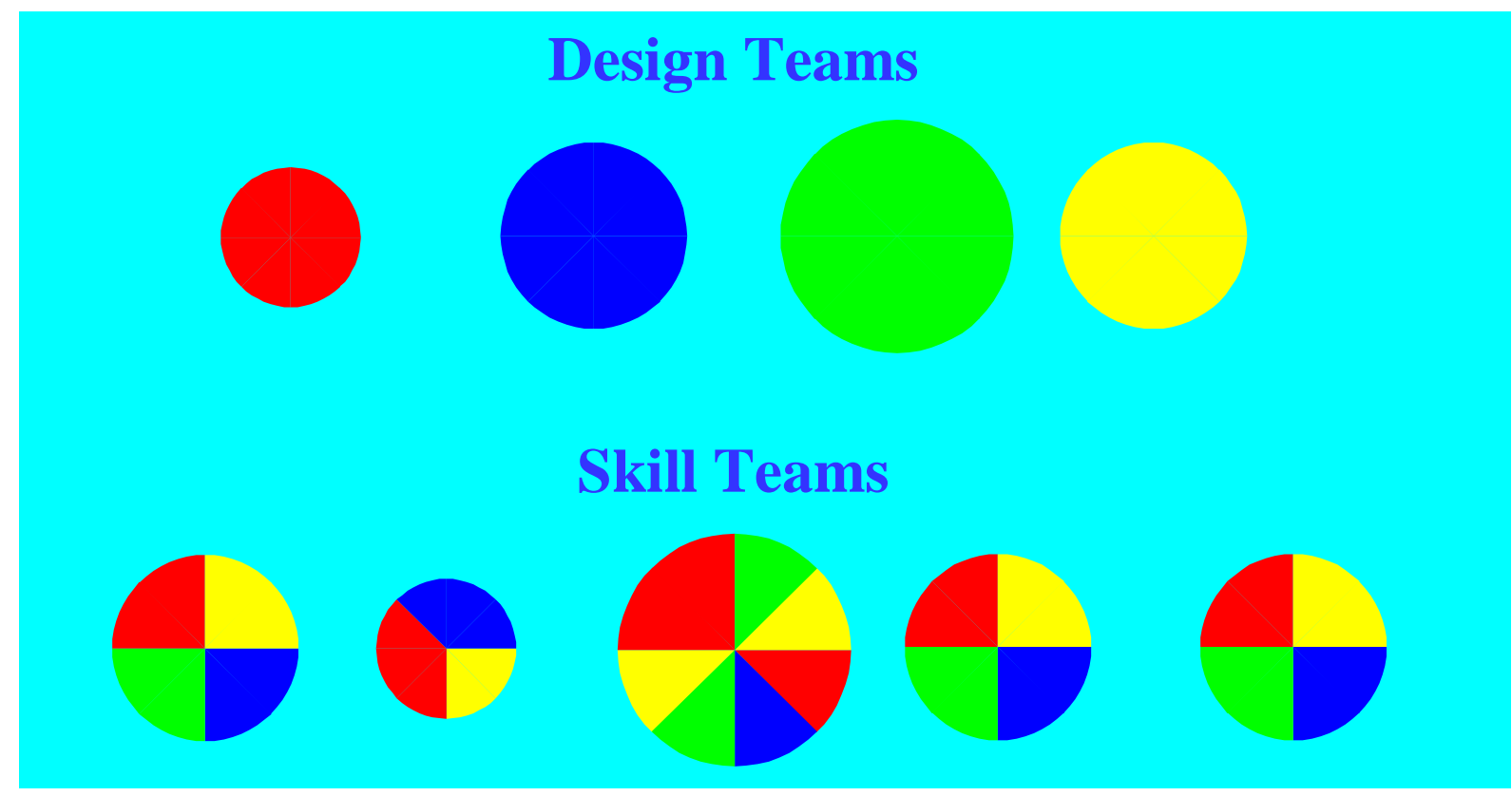

Figure 1: An illustration of the cross-functional teaming model. 
teams works on a specific engineering design project as part of a single company's engineering staff (Spartan Embedded Technologies) to meet a customer's needs. Skill teams are formed from representatives of each design team, as illustrated in Fig. 1. As an example, Fig. 1 depicts four design teams and five skill teams, the latter of varying size and membership. As the name implies, skill teams learn specific skills needed to ensure success within the individual design projects. For example, a skill team may focus on project management or on a computer-based design/test tool. Skills brought back to design teams must be shared with other members. Skill teams are highly focused, and the intent is to foster self-directed learning, so as to reinforce both lifelong-learning as well as learning by teaching others (i. e., a learn-do-teach paradigm). The interaction facilitated by skill teams that cross design-team boundaries has been a key aspect of the teaming experiences gained by the students.

The CFT model was designed in accord with two learning paradigms: formal cooperative learning, as described by Smith and Waller, in which students work together in base groups to maximize their own and each others' learning ${ }^{11}$; and cooperative jigsaw strategy, by Aronson et al., in which specialized teams are formed from representatives of base groups ${ }^{12}$. Moreover, the CFT course learning model is representative of what students will encounter in industry. For example, Ward has documented the formation of "study groups" to facilitate staff professional development through self-directed learning ${ }^{13}$.

The function of the skill teams in ECE 482 has been twofold: professional and communication skills in support of the engineering design process, and technical skills within sub-disciplines of electrical and computer engineering. The expertise of a skill team is comprised of prior knowledge learned by members in other courses and of just-in-time knowledge learned specifically to meet the needs of the design project. Typical professional/communication skill teams include project/course management, document preparation, and web development. Technical skill teams have ranged from sensor interfacing to software engineering. Each design team has at least one member on the management, web, and documentation skill teams. These skill teams last for the duration of the semester. Representation on technical skill teams is determined according to design-team needs. For example, consider Table 1, which depicts a matrix of skill relationships among design teams. The four teams were involved with a project based on a ping-pong ball system with sensors and actuators to emulate a fluid-flow control system: a ping-pong ball in a tube is controlled by airflow and its position is sensed. In Table 1, rows are organized according to the product or subsystem being developed (where the system

Table 1: Design-team skill matrix for prototype fluid-flow control system.

\begin{tabular}{|c|c|c|}
\hline & $\begin{array}{c}\text { Strategy 1: } \\
\text { Microcontroller }\end{array}$ & $\begin{array}{c}\text { Strategy 2: } \\
\text { Emulator }\end{array}$ \\
\hline $\begin{array}{c}\text { Product 1: } \\
\text { In-system-programmable logic } \\
\text { device programmer } \\
\text { (discipline: digital systems) }\end{array}$ & Design Team 1 & Design Team 2 \\
\hline $\begin{array}{c}\text { Product 2: } \\
\text { Ping-pong ball position controller } \\
\text { (discipline: control systems) }\end{array}$ & Design Team 3 & Design Team 4 \\
\hline
\end{tabular}


may be viewed as a sub-discipline of ECE); and columns, the design strategy being applied. A row or column corresponds to a possible skill team having expertise with a sub-discipline, methodology, or tool. For example, associated with the second row, a skill team was formed to study fluid-flow control systems, comprised of members from design teams 3 and 4. Similarly, in the second column, design teams 2 and 4 were represented on a skill team learning about the use of a PC-based emulation tool, such as LabVIEW®. Such skill teams exist only as long as needed to accomplish their designated purpose. Students are encouraged to propose and form new skill teams as needed, thus empowering them to take responsibility for managing their own learning. The model provides some class-wide cohesion among design teams by leveraging their common threads through CFT. Students are introduced to strategies for effective teaming, group processing, and self-assessment ${ }^{14}$.

In addition to the use of CFT, our experiences with multidisciplinary engineering design in ECE 482 include multidisciplinary projects and multidisciplinary teaming. A multidisciplinary project is an engineering design project that requires core knowledge from a discipline outside of electrical and computer engineering. In ECE 482, this typically occurs when a customer from another discipline initiates a project. For example, a mechanical engineering customer requested a web-based application to monitor and control experiments with a motor system. An ECE-only design team in the ME laboratory with technical support from ME staff conducted this project. As another example, a physiology customer wanted a Windows ${ }^{\circledR}$ PC-based system to project light patterns onto cells through a microscope and record the impulses that are generated. An ECE-only design team also performed this project with support from the physiology research lab. On the other hand, multidisciplinary teaming refers to an engineering design project that is completed by a team of students from various disciplines. This has occurred once in ECE 482, in coordination with the capstone course in mechanical engineering, ME 481-Mechanical Engineering Design Projects ${ }^{15}$. An ECE team paired with an ME team to design and build a computer-controlled model of the Earth and its rotation, powered by renewable energy sources. This project required an intensive collaborative effort by members of both teams. In both cases, students learned some aspects of another discipline during the design process; however, the expertise resided locally with staff or students in a specific discipline.

\section{Lessons Learned and Possibilities}

These three avenues for multidisciplinary design experiences have yielded a range of results and present several opportunities for reform. Students, employers, and educators have given the CFT model across the board. Educators have commented on its active learning qualities, and employers, its relevance to real-world practices. Students, who complete self-assessment reports at the end of the semester, have reflected on CFT and many have cited it as one of the key experiences in the course. Most students do not understand it at the beginning of the semester, but by the end, they recognize its benefits. One student wrote: "This class has been amazing. While the classroom puts an emphasis on the teaming aspect of learning, technical concepts fall into place because the goal is to complete a tangible product by the semester's end. The most valuable lessons learned in ECE 482 are the benefits of relying on each other, whether the task is working on code or circuitry, writing part of a report, gathering research materials, brainstorming, or boosting team spirit." One student used the saying "it's not what you know, it's who you know" to describe the synergistic effect of having team members with diverse skills to 
apply to a project. For some students, the CFT experience has changed their outlook on an engineering career, since they see engineering design as less isolated in single individuals and disciplines.

Students who have participated in multidisciplinary projects or multidisciplinary teaming tend to achieve a greater appreciation for the concept of CFT, since their project has required core knowledge from other disciplines. However, the students also are keenly aware of the potential problems with multidisciplinary design, due to the challenges of just-in-time learning in other disciplines and/or working with experts in other disciplines. Students have made the following recommendations for multidisciplinary teaming, specifically in the context of comprising design team members from capstone courses in different departments:

- A disciplinary team must be well organized and well trained before collaborating with teams from other disciplines.

- A regularly scheduled, common meeting time for members from all disciplines is essential to share ideas and foster multidisciplinary, critical thinking. An agenda is important so those members may prepare in advance given the potential breadth of topics.

- The disciplinary teams should synchronize their tasks according to a common timeline, even if respective departmental capstone courses are not coordinated.

- Communication about progress in all areas is critical to maintain a high level of cooperation and interdependence and to minimize problems and delays.

- Members should attempt to balance the effort of working within their discipline and working with other disciplines.

- Differences in disciplines should be kept in mind:

$>$ Different departmental capstone courses may have different requirements and expectations.

$>$ The strategies and processes for solving design problems may vary between disciplines.

For example, electrical and computer engineers often use flow charts as an initial specification for hardware and software systems; whereas mechanical engineers use drawings and risk analysis.

$>$ Despite the fact that each member has special knowledge and skills within a discipline, each person should develop an appreciation for or understanding of the major design elements under the purview of other disciplines. Meeting system-level, multidisciplinary design requirements may require an integration of information across the disciplines.

Although student observations point to the importance of acquiring knowledge and skills in other disciplines, we have found that skill development via the avenues of multidisciplinary projects and teaming in ECE 482 is very problem-specific and difficult to re-use. Alternatively, to bring students from near "ground zero" toward a working knowledge in another discipline requires numerous training sessions on a relatively steep learning curve under time constraints. The multidisciplinary, cross-functional teaming experience would be enhanced if students brought some key multidisciplinary engineering knowledge and skills into the capstone engineering 
design environment. Under such a model, students would come into a capstone course with backgrounds that differ in both depth and breadth and with better preparation to address multidisciplinary problems.

\section{Essential Elements for Systemic Reform}

Recent reports have called for a change in the historical approach to post-secondary teaching and learning, one based less on the teacher and more on learning and the learner ${ }^{16,17}$. Much has been written about the need to reform instructional processes, to legitimize the scholarship of teaching, and to better relate student learning experiences to professional practice ${ }^{16,18}$. Yet strategies to enhance learning in engineering, science, and mathematics have had marginal success and limited evidence of institutionalization of innovations even when successful. A recent evaluation of the many projects funded by NSF Undergraduate Course and Curriculum Development Program demonstrated a positive effect of many instructional and curricular innovations with limited evidence of dissemination and adoption of innovations beyond the principal investigator, much less beyond the host institution ${ }^{19}$. More generally, despite spending more than $\$ 210$ million on post-secondary educational innovations in engineering and related sciences since 1991, the National Science Foundation acknowledged its failure to reform core post-secondary instructional practices when it issued a separate Systemic Reform Initiative to institutionalize existing teaching and learning innovation efforts.

As an example, consider the engineering professor determined to improve the lowest-rated (by students) course taught in his institution by incorporating active learning principles into it. The professor invested many hours in learning to use group instruction, portfolio assessment, and open-ended design exercises. He found these practices both more time consuming than the traditional lecture/discussion format and more effective in enhancing student achievement. The students responded by rating the course very highly and extolling its virtues to other students. Other faculty members and staff from industry were impressed by the preparation of students and by the quality of their design work. By all accounts, the innovation was a success. Yet the departmental faculty rejected a petition to revise the traditional course format permanently because of the extra time commitment and the belief that such an investment was not important in promotion and tenure decisions. Faculty members teaching the course the next year returned to its traditional lecture format ${ }^{20}$.

The failure to institutionalize instructional innovations and to transform academic departments and programs into learner-centered environments reflect the lack of a systemic perspective ${ }^{21-23}$. By systemic perspective we mean a process of innovation that accounts for the interrelationships among the array of external, institutional, departmental, and individual factors influencing academic departments, faculty work, and student learning. Even when instructional innovations focus on learning rather than or in addition to teaching, the presumed "model" of how these factors combine to affect teaching and learning-what O'Banion ${ }^{17}$ and others would call "the architecture of teaching and learning"-often is not consistent with a learner-centered environment.

Many instructional focus solely on the individual faculty member and his or her instructional responsibility. Some efforts acknowledge a wider range of faculty work responsibilities and 
place the faculty member in a departmental context. Few reform efforts incorporate the array of institutional and external factors potentially affecting the effectiveness and institutionalization of the innovation.

Without incorporating a more systemic approach, most change efforts have been relegated to the individual level - enhancing learning and learning productivity through improving classroom pedagogy. Weimer's ${ }^{24}$ work on effective teaching, Angelo and Cross' ${ }^{25}$ models of classroom assessment, and many other types of instructional development programs focus on improving the individual professor's instructional style without addressing the academic architecture directly. The underlying assumption here is that the academic culture can be transformed from teacher- to learner-centered by the cumulative effects of reforming individual teachers and teacher beliefs in their classrooms. Yet the assumption that institutional or even departmental change is somehow a result of aggregated changes in individual faculty beliefs and behaviors is unproven, even discredited ${ }^{19}$.

Even if the emphasis is on learning, strategies to improve pedagogy fail to take into account the complexity of faculty work. In addition to teaching, depending on the type of institution faculty are expected to carry out research and scholarship, improve curricula, and contribute to institutional, community and public service ${ }^{26}$. Strategies to improve teaching that do not account for the potential effects on other aspects of faculty work are likely to fail. Without a systems perspective, interventions impact singular aspects of complex problems and often result in unintended outcomes unrelated to the actual goal. For example, the Ohio legislation requiring faculty in public institutions to spend $10 \%$ more time teaching in 1995 than they did in $1990^{27}$ or institutional policies demanding increasing numbers of web-based courses, may increase productivity by traditional measures of student contact hours and result in increased teaching efficiency. These efforts are not equivalent, however, to increases in student learning, and often do not even take learning into account. The productivity measures themselves need to be modified to account for learning outcomes rather than serving strictly as indicators of head count and tuition generation ${ }^{28}$.

Both classroom efforts and seamless learning initiatives occur within organizational structures, policies, and practices. The first step in successfully institutionalizing learning innovations is to specify the system in which the institutional innovation takes place. This system includes the local academic culture(s) ${ }^{29-33}$ : external environment (accrediting agencies, legislature, industry, federal and state policies/programs, disciplinary societies, resources), institution/college (rewards, institutional resources, workload policies, availability of staff support, technological infrastructure, institutional conditions such as size, nature and diversity of students), departments (rewards, departmental resources, composition of the faculty, diversity of students, admissions policies, workload policies), faculty work (teaching, research, service, motivation/socialization of faculty) and student learning.

The second step is to identify problems and potential solutions in this systems context. For example, the limited use of active learning instructional approaches by faculty members teaching engineering service courses may reflect the minimal rewards and limited credit in departmental workload allocation for these courses as much as it does the predisposition of the faculty. 
Finally, implementation of any instructional innovation must start with institutionalization as the ultimate goal. We explore the implications of these elements of systemic reform for engineering service courses below.

\section{Lessons Learned}

Using interview data and data on student learning outcomes from the service course reform effort at Michigan State, we examine four systemic factors in detail: elaboration of the system for service courses, service course dynamics, the roles of values and rewards, and strategies for achieving sustainable innovation.

\section{Elaboration of the System for Engineering Service Courses}

- Although service courses are often the responsibility of a single department, their success depends on close cooperation with the other departments whose students take the courses. Such cooperation includes identification of learning outcomes, sharing problem sets, and determining where the service courses best fir the curricula in the relevant departments.

- Student and faculty complaints about a service course may reflect inconsistencies in course taking (i.e., taking a course meant for sophomores while a senior), incoherent curricula, and other factors in addition to instructional practices and course content.

- Department chairs affect individual service courses by the faculty they assign to teach them, by the workload credit given for teaching these courses, and the by rewards allocated to faculty teaching them. Consider workload policies. At MSU faculty are given credit for teaching one course whether or not it's 230 students in a service course or 5 students in a graduate seminar. The current work allocation formula works against a major investment in faculty time in reforming service courses.

- Innovative instructional approaches developed for service courses as part of a funded research project must be placed in the context of the typical faculty member's level of support. For example, labor intensive instructional approaches requiring release time and substantial additional effort will make it unlikely that many faculty members will use the new instructional approaches.

- Institutional policy that prohibits students from declaring an engineering major until the junior year adversely affects service courses meant for first- and second-year students.

- Institutional and state policies that put pressure on engineering programs to minimize the number of credits required to earn a degree adversely affect reform efforts that require either additional credits or a reallocation of credits within a major.

- $\mathrm{ABET}$ is an important lever for change even when the innovation is focused on a single service course.

\section{Service Course Dynamics}

- Responding to several "client departments" puts pressure on faculty teaching service courses to deliver too much material often without regard to how well students learn the material.

- The primary "client" of a service course is often the college rather than a particular department, which makes it difficult for faculty and department chairs in a department to value the course unless the college gives it high priority. 
- Faculty teaching service courses must often confront very uneven preparation by students from different majors, which discourages the faculty from spending substantial time reforming a service course.

- The number of students enrolled in a service course is often a stronger determinant of instructional style and learning environment than the desired learning objectives. This dynamic cannot be overcome without substantial college and departmental support for faculty members teaching these courses.

\section{Values and Rewards}

- The history of service courses influences the value that faculty place on them. If assignment to teach a service course is seen as a punishment or as the course where the worst teachers or poorest researchers are assigned then finding faculty volunteers to teach a revised course is problematic.

- Teaching a service course contains disincentives for faculty members and for the department chair. Students from other majors seldom end up enrolling as graduate students in the home department, a disincentive for the chair, and faculty teaching service courses wonder about their value in promotion and tenure relative to teaching advanced courses in the major, a disincentive for the faculty.

- Finding a way to give credit toward promotion and tenure is a crucial part of encouraging faculty involvement in reforming engineering service courses. One mechanism is to give substantial weight to obtaining externally funded grants focused on teaching and learning.

- Faculty understand that the investment a department makes in its service courses-the dollars and support assigned to them-reflect the value the department places on thee courses.

\section{Innovation Strategies}

- Obtaining the support of the various departmental chairs and curriculum committees is as crucial to institutionalizing service course reforms as improving the instructional strategies in the classroom.

- Review the place the service course has in other majors; i.e., is it a requirement, where does it fit in the curriculum, what do faculty in other departments expect of the course?

- Reform efforts must be cost effective (acknowledged in faculty rewards, not too labor intensive, and producing gains in student learning) to encourage additional faculty members to teach service courses.

- Service courses work best when their instructional approaches and content knowledge are reinforced in subsequent (or previous) courses. This reform requires cooperation and coordination with the faculty members teaching these other courses.

- One way to increase the value of service courses is to have the department chairs and senior faculty members take turns teaching the course. 
- Support staff are crucial to reforming service courses. Laboratory technicians must coordinate their lab experiments with lectures. Time must be given to train teaching assistants in the manner the instructor desires.

- Appointing a team of faculty to take charge of a service course is more likely to lead to institutionalized reforms than assigning a single faculty member to the task. However, this approach requires substantially more lead-time in developing course materials.

- Benchmark with peer institutions and departments to identify best practices. Use this information to help convince local faculty members to support the instructional innovation.

\section{Discussion}

We are currently in the process of sharing what we have been learning about the reform of engineering service courses with various faculty, student, alumni and administrative groups within the College of Engineering. From these discussions, we plan to identify a strategy for moving forward with plans to better link these courses to follow-on courses within the major, including the major engineering design experience.

We have also come to conclude that what we have learned about course and curriculum reform while focusing on the role of the engineering service course within the curriculum can be applied elsewhere within the engineering curriculum, as we seek ways to continuously improve specific engineering academic programs. Hence, we will attempt to apply what we have learned here more broadly, as proposals are put forward to make major changes within a specific course or for proposed changes with respect to the educational program objectives or outcomes for a specific academic program.

\section{Acknowledgements}

This work was supported in part by the General Electric Fund through a grant entitled "Reforming the Early Undergraduate Engineering Learning Experience." It also was sponsored in part by NSF grants CDA-9700732 and ACI-9624149. The authors would like to acknowledge the assistance provided by Mr. Nathan Robinson and Mr. Eric Warmbier in collecting the data for the ECE 345 benchmarking; and Mr. Brian Rennells for summarizing the ECE 482 multidisciplinary teaming experiences.

\section{Bibliography}

1. Fisher, P.D. \& Fairweather, J.S. Transforming engineering service courses. Proc. of the 1999 Frontiers in Education Conference. San Juan, PR. Nov. 10-14, 1999. CD-ROM.

2. Fisher, P.D. Assessment process at a large institution. Proc. of the 1998 ASEE Annual Meeting and Exposition. Seattle, WA. June 28-July 1, 1998. CD-ROM.

3. Criteria for Accrediting Programs in Engineering in the United States: Effective for Evaluations During the 1998-99 Accreditation Cycle. Engineering Accreditation Commission, Accreditation Board for Engineering and Technology. Baltimore, MD. pp. 5-7. 
4. URL: http://www.abet.ba. md.us/EAC/eac2000.html. ABET Engineering Criteria 2000. Engineering Accreditation Commission, Accreditation Board for Engineering and Technology. Baltimore, MD.

5. Graulau, J., Kari, S., Masten, S.J. \& Sticklen, J. A Web-based \& group learning environment for an introductory environmental engineering course. Proc. of the 1999 Frontiers in Education Conference. San Juan, PR. Nov. 10-14, 1999. CD-ROM.

6. URL: http://www.egr.msu.edu/ece/Information/Academics/Courses/Syllabi/ECE345_syllabus.html. Course Syllabus for Electronic Instrumentation Systems (ECE 345). Michigan State University. East Lansing, MI.

7. URL: http://www.egr.msu.edu/ugs/degree1.htm. Undergraduate Degree Programs in the College of Engineering. Michigan State University. East Lansing, MI.

8. URL: http://www.usnews.com/usnews/edu/college/rankings/cat13wi.htm. Best undergraduate engineering programs... U.S. News \& World Report. New York, NY.

9. URL: http://www.egr.msu.edu/classes/ece482. ECE 482 Course Web Site. Michigan State University. East Lansing, MI.

10. Rover, D.T. \& Fisher, P.D. Cross-Functional Teaming in a Capstone Engineering Design Course. Proc. of ASEE/IEEE 1997 Frontiers in Education Conference. November 5-8, 1997. CD-ROM.

11. Smith, K.A. \& Waller, A.A. Cooperative Learning for New College Teachers. New Paradigms for College Teaching. edited by Campbell, Wm.E. and Smith K.A., pp. 185-209. Interaction Book Company, Edina, Minnesota. (1997).

12. Aronson E., et al. The Jigsaw Classroom. Sage. (1978).

13. Ward, N. Improving Technical Knowledge Through Study Groups. Raytheon E-Systems Falls Church, Software Development - East Conference. Washington, D.C. October 1997. Also see URL: http://www.egr.msu.edu/classes/ece482/docs/sd97.pdf.

14. Aldridge, M.D. \& Lewis, P.M. Multi-disciplinary Teams: How to Assess and Satisfy ABET Criteria. Symposium on Best Assessment Processes in Engineering Education. Rose-Hulman Institute of Technology. Terre Haute, Indiana. April 11-12, 1997. Also, see URL: http://www.eng.auburn.edu/center/twc.

15. URL: http://www.egr.msu.edu/me/undergraduate/designProgram/. ME 481 Web Site, Michigan State University. East Lansing, MI.

16. Boyer, E. Scholarship Reconsidered: Priorities of the Professoriate. Princeton, N.J.: Carnegie Foundation for the Advancement of Teaching (1990).

17. O'Banion, T. A Learning College for the $21^{\text {st }}$ Century. Phoenix, Ariz.: Oryx Press. (1997).

18. National Research Council. Improving Engineering Design. Washington, D.C.: National Academy Press (1991).

19. Eiseman, J. \& Fairweather, J. Evaluation of the National Science Foundation Undergraduate Course and Curriculum Development Program: Final Report. Washington, D.C.: SRI International (1996).

20. Fairweather, J. Faculty Work and Public Trust: Restoring the Value of Teaching and Public Service in American Academic Life. Boston: Allyn and Bacon (1996).

21. Argyris, C. \& Schon, D. Organizational learning: A Theory of Action Perspective. Reading, Mass.: AddisonWesley (1978).

22. Kast, F. \& Rosenzweig, J. Organization and Management: A Systems and Contingency Approach. $4^{\text {th }}$ ed. New York: McGraw-Hill (1985).

23. Senge, P. \& Associates The Fifth Discipline: The Art and Practice of the Learning Organization. New York: Doubleday (1990).

24. Weimer, M. Improving College Teaching: Strategies for Developing Instructional Effectiveness. San Francisco: Jossey-Bass (1990). 
25. Angelo, T. \& Cross, K. Classroom Assessment Techniques: Handbook for College Teachers. $2^{\text {nd }}$ ed. San Francisco: Jossey-Bass (1993).

26. Bowen, H. \& Schuster, J. American Professors: A National resource Imperiled. New York: Oxford University Press (1986).

27. Cage, M. Regulating faculty workloads. Chronicle of Higher Education. January 20, p. A30, A33 (1995).

28. Colbeck, C. \& Fairweather, J. Enhancing faculty contributions to learning productivity. Paper presented at the Annual Meeting of the Association for the Study of Higher Education, San Antonio, Texas (1999).

29. Tener, R. Outcomes assessment and the faculty culture: Conflict or congruence? Journal of Engineering Education 88:61-72 (1999).

30. Blackburn, R. \& Lawrence, J. Faculty at Work: Motivation, Expectation, Satisfaction. Baltimore: Johns Hopkins University Press (1995).

31. Braskamp, L. \& Ory, J. Assessing Faculty Work: Enhancing Individual and Institutional Performance. San Francisco: Jossey-Bass (1994).

32. Guskin, A. Reducing student costs and enhancing student learning: Restructuring the role of faculty. Change. (September/October: 16-25, 1994).

33. Seldin, P. \& Associates How Administrators Can Improve Teaching. San Francisco: Jossey-Bass (1990).

\section{P. DAVID FISHER}

David Fisher is a Professor of Electrical and Computer Engineering at Michigan State University. He serves at Project Director and Principal Investigator for the GE Fund-sponsored project: "Reforming the Early Undergraduate Learning Experience." Dr. Fisher is a registered Professional Engineer in the State of Michigan and is an ABETIEEE Program Evaluator for EC2000 computer engineering and electrical engineering programs.

\section{JAMES S. FAIRWEATHER}

James Fairweather is a Professor of Higher Education and Deputy Director of the Center for the Study of Advanced Learning Systems at Michigan State University. He authored Faculty Work and Public Trust, a book aimed at increasing the value placed on teaching and public service at American colleges and universities. He was the original evaluator for the ECSEL coalition.

\section{DIANE T. ROVER}

Diane Rover is an Associate Professor of Electrical and Computer Engineering at Michigan State University. She is a Principal Investigator for the project "Visions for Embedded Systems Laboratories" sponsored by the National Science Foundation Combined Research-Curriculum Development Program. She serves as the Director of the undergraduate program in Computer Engineering. Dr. Rover received an NSF Career Program award in 1996.

\section{LISA A. HASTON}

Lisa Haston is a doctoral student in Educational Administration at Michigan State University. She received her B.A. in German and M.A. in Educational Administration: Student Affairs at MSU. Previous to her doctoral studies, Ms. Haston directed the Academic Resource Center and was on the faculty at Olivet College, Olivet, Michigan. Ms. Haston currently holds two graduate research appointments, and is involved in the Tech Prep Initiative in Michigan. 